\title{
HET BEROEPSGEHEIM VAN DE ACCOUNTANT IN OVERHEIDS- DIENST
}

\author{
door L. van Essen Lzn.
}

De redactie heeft mij verzocht enkele beschouwingen te geven naar aanleiding van de prae-adviezen van de heren W. N. de Blaey, J. A. M. F. Lindner, ec. drs., H. B. J. Sanders en J. Toutenhoofd. Deze praeadviezen werden uitgebracht in een bijeenkomst op 17 Mei 1947 van de besturen van het Nederlands Instituut van Accountants en de Vereniging van Academisch Gevormde Accountants met de leden dezer organisaties die in overheidsdienst werkzaam zijn en ze werden gepubliceerd in de nummers van het M.A.B. van Juni en Juli van dit jaar.

Gaarne voldoe ik aan dit verzoek, in de hoop dat een vruchtbare gedachtenwisseling moge volgen.

Het algemene vraagstuk van het beroepsgeheim van de accountant is, de redactie van het M.A.B. heeft het in haar inleiding in het nummer van Juni 1948 terecht opgemerkt, niet nieuw. Ik heb dit onderwerp in een studievergadering van het N.I.v.A. in April 1936 mogen inleiden en daarna heb ik op de 31 ste accountantsdag van 30 November 1946 mogen spreken over: "Het beroepsgeheim, in het bijzonder dat van de accountant." Ook is in de vakpers het beroepsgeheim van de accountant verschillende malen ter sprake gekomen. De vier genoemde prae-adviezen behandelen evenwel een bijzondere zijde van het vraagstuk: het beroepsgeheim van de accountant die in overheidsdienst is, van de functionaris dus die ik in mijn inleiding van de 31 ste accountantsdag heb genoemd de ambtenaar-accountant.

Reeds uit de door mij gebruikte naam: ambtenaar-accountant, volgt dat $\mathrm{ik}$ in de bedoelde functionaris in de eerste plaats zie de ambtenaar, als zodanig onderworpen aan publiekrechtelijke voorschriften, dus aan:

art. 59. Algemeen Rijksambtenarenreglement (K.B. 12 Juni 1931) luidend:

„1. De ambtenaar is verplicht tot geheimhouding van hetgeen hem in ,zijn ambt ter kennis is gekomen, voor zover die verplichting uit de aard ,der zaak volgt of hem uitdrukkelijk is opgelegd.

.2. De in het vorige lid bedoelde verplichting bestaat niet tegenover "hen, aan wie de ambtenaar onmiddellijk of middellijk ondergeschikt is, ",noch in zover hij door een boven hem gestelde van de verplichting tot "geheimhouding is ontheven."

en aan:

art. 162 Wetboek van Strafvordering, luidend:

„Openbare colleges of ambtenaren, die in de uitoefening hunner bedie,ning kennis bekomen van een strafbaar feit met welks opsporing zij niet "zijn belast, zijn verplicht daarvan onverwijld aangifte te doen, met ",afgifte van de tot de zaak betrekkelijke stukken, aan de officier van ,justitie of aan een zijner hulpofficieren, of wel, indien het betreft een "strafbaar feit waarvan het kantongerecht kennis neemt, aan de ambte",naar van het openbaar ministerie bij het kantongerecht."

Dit standpunt wordt gedeeld door de prae-adviseurs de Blaey en Sanders: ook zij zien in de ambtenaar-accountant in de eerste plaats de ambtenaar. 
Welke zijn daarvan de consequenties met betrekking tot het beroepsgeheim.

De Blaey behandelt in zijn prae-advies de beide kanten van het „vraagstuk der geheimhouding", t.w. de zwijgplicht en het zwijgrecht (het recht van verschoning) afzonderlijk.

T.a.v. de eerste, de zwijgplicht, merkt hij op accoord te gaan met mijn mening uitgesproken op de 31 ste accountantsdag, dat art. 162 Wetboek van Strafvordering de ambtenaren-accountants verplicht, als zij een misdrijf of een overtreding ontdekken, die niet ligt op het terrein van hun dagelijks werk, daarvan mededeling te doen aan de bevoegde autoriteiten. In dat opzicht bestaat er voor hen geen plicht tot geheimhouding. 1) Intussen zijn er, naar de Blaey mededeelt, maatregelen getroffen om ongewenste consequenties te voorkomen; b.v. kan het gewenst zijn voor te schrijven dat dergelijke aangiften eerst mogen geschieden nà verkregen sanctie. „Zo bestaat bij de Rijksaccountantsdienst het voorschrift dat in dergelijke gevallen het feit aan het Ministerie van Financiën ter kennis gebracht moet worden, waarna deze (d.i. dus de Minister van Financiën, v. E.) dan al of niet voor doorzending aan ambtgenoten zorg draagt". 2) Bij de Rijksaccountantsdienst wordt dus onbeperkte toepassing van art. 162 Wetboek van Strafvordering niet toelaatbaar geacht: normaal zullen de rijksaccountants zich niet inlaten met strafbare feiten op economisch gebied. Maar het kan wel eens gewenst zijn, zegt de Blaey, dat, om aan bepaalde misstanden een einde te maken, zeer hard wordt toegeslagen, b.v. door samenwerking tussen alle overheidsinstanties. In zo'n geval zal echter altijd het Min. van Financiën moeten worden gekend. ${ }^{3}$ ) M.a.w., de rijksaccountants geven de door hen geconstateerde strafbare feiten ten aanzien van de naleving der wetten, waarin zij niet nadrukkelijk als opsporingsambtenaar zijn genoemd, door aan het Min. van Financiën; de Minister van Financiën beslist wat verder zal gebeuren.

Komt nu de ambtenaar-accountant, die aan zijn hoogste chef, dus b.v. de Minister van Financiën, de Minister van Economische Zaken, de Minister van Landbouw, Visserij en Voedselvoorziening, mededeelt dat hij bij zijn onderzoek naar de naleving van belastingwetten, van prijsvoorschriften, van distributievoorschriften, een strafbaar feit heeft geconstateerd liggende op een ander gebied dan waarop hij werkzaam is, in botsing met de hem in art. 2 van het Reglement van Arbeid van het Nederlands Instituut van Accountants opgelegde geheimhoudingsplicht? 4)

De Blaey zegt dienaangaande, dat in 't bijzonder ,de externe accoun „,tants, duidelijker gezegd de opsporingsambtenaren bezwaar zullen "moeten maken tegen elke eis van geheimhouding, uitsluitend gegrond op .,beroepsoverwegingen. Deze is voor hen onaanvaardbaar ter wille van de goede uitoefening hunner functie als ambtenaar." 5) Ik zou hier willen opmerken, dat, omdat de ambtenaar-accountant opsporingsambtenaar is, onder zijn algemene opdracht ook valt het rapporteren van strafbare fei-

1) De Accountant, orgaan van het N.I.v.A., December 1946, blz. 48.

2) M.A.B. Juni 1948, blz. 170.

3) M.A.B. Juni 1948, blz. 170.

4) Lid 1 van art. 2 R.v.A. luidt: De leden zijn gehouden hun arbeid te verrichten met eerlijkheid, nauwgezetheid en onzijdigheid. Het is hun verboden betreffende hetgeen hun in de uitoefening van het accountantsberoep ter kennis is gekomen, voor zover dit een vertrouwelijk karakter draagt, andere mededelingen te doen dan de uitvoering van de opdracht vereist.

5) M.A.B. Juni 1948, blz. 171. 
ten, met welker opsporing hij niet is belast, doch waarvan hij in de uitoefening zijner bediening heeft kennis bekomen (art. 162 Strafvordering): de uitvoering van die algemene opdracht kan vereisen het doen van aangifte. De ambtenaar-accountant zou zijn plicht tot geheimhouding eerst schenden, wanneer hij aan anderen dan de bevoegde autoriteiten van die strafbare feiten mededeling zou doen. De Blaey komt tot dezelfde conclusie; hij zegt niet te geloven dat overheids-accountants door art. 2 van het R.v.A. van het N.I.v.A. in moeilijkheden zullen geraken. ${ }^{6}$ )

Met betrekking tot het $z$ wijgrecht (verschoningsrecht) vraagt de Blaey zich af, of de overheids-accountant zich heeft te richten naar de hem als ambtenaar gegeven voorschriften, of hij zich heeft te beroepen op het "algemene verschoningsrecht" of op het bijzondere verschoningsrecht, voortvloeiende uit art. $19463 \mathrm{e} \mathrm{B.W}$. Hij antwoordt: naar de voorschriften hem als ambtenaar (eventueel) gegeven. $\mathrm{Hij}_{\mathrm{ij}}$ voegt daaraan toe dat voor de ambtenaar-accountant bij de Rijksaccountantsdienst geen voorschriften door het Ministerie van Financiën zijn gegeven: die moeten dus zelf beslissen of ze zich al dan niet op een verschoningsrecht zullen beroepen.

Ik herinner in dit verband aan een beslissing van 23 Januari 1936 van de rechter-commissaris Mr. M. D. K. S. van Lier, opgenomen in het M.A.B. van Juli 1937 en van een commentaar voorzien door Mr. Th. Limperg. Het ging over het volgende geval: een accountant van de directe belastingen (thans geheten accountant bij de Rijksaccountantsdienst) was opgeroepen om getuigenis af te leggen met betrekking tot de vraag of de boekhouder van een bedrijf, waarbij de accountant een onderzoek had ingesteld, zich niet goed van zijn taak had gekweten. De accountant wenste zich van het afleggen van getuigenis te verschonen uit hoofde van zijn beroep van accountant bij de directe belastingen. De rechtercommissaris heeft toen een beslissing gegeven, waaraan het volgende is ontleend:

„Overwegende, dat artikel 1946, 3e B.W., dit verschoningsrecht toe,kent aan alle degenen, die uit hoofde van hun stand, beroep of wettige ,,betrekking tot geheimhouding verplicht zijn, doch alleen en bij uitslui,ting nopens hetgeen waarvan de wetenschap aan hen als zodanig is toe,vertrouwd;

„Overwegende, dat deze verplichting van deze getuige wordt omschre,ven in de Wet, en wel in de Wet op de Inkomstenbelasting in artikel „102 en in de Wet op de Vermogensbelasting in artikel 52, en mitsdien ",deze verplichting niet verder reikt dan haar omschrijving daar gegeven;

"Overwegende, dat genoemd artikel 102 de belasting-ambtenaar ge„,heimhoudingsplicht oplegt nopens inkomen, opbrengst, uitdelingen, en ,,in het algemeen nopens de zaken of werkzaamheden van een ander; en .,genoemd artikel 52 nopens iemands vermogen;

„Overwegende, dat mitsdien getuige's verschoningsrecht niet verder ,,reikt dan nopens inkomen, opbrengst, uitdelingen, de zaken of werk,zaamheden of vermogen van een ander:

„Overwegende, dat daarvan hier niet de rede is, immers de te stellen „,vragen blijkens genoemd vonnis slechts betreffen de vraag of eiser al of .,niet goed gehouden heeft de boeken van gedaagde, en deze vragen kun",nen worden beantwoord zonder iets te openbaren omtrent inkomen, uit",delingen, zaken, werkzaamheden en vermogen van een ander, en de .,getuige onder voorbehoud van beantwoording van slechts dusdanige ,vragen getuigenis kan afleggen;

B) M.A.B. Juni 1948 , blz. 171 .

\section{m a b blz. 268}


,Rechtdoende:

.Beslissen, dat de getuige zich in deze niet vermag te verschonen en "verplicht is onder dit voorbehoud getuigenis af te leggen".

Uit deze beslissing mag worden geconcludeerd dat het beroep van de betrokken accountant op een verschoningsrecht wèl zou zijn geaccepteerd als hem getuigenis was gevraagd met betrekking tot zaken waaromtrent hem als ambtenaar in de genoemde wetten geheimhouding is opgelegd.

Aan het slot van zijn prae-advies merkt de Blaey op, dat de overheidsaccountant, in het bijzonder als opsporingsambtenaar, soms inbreuk zal moeten maken op het beroepsgeheim van de openbare accountant. Inderdaad komt hierdoor de openbare accountant in een niet bijzonder aangename toestand te verkeren: hij zal hebben te overwegen wat hem te doen staat. Ik ga op deze kwestie hier niet verder in: zij ligt m.i. buiten het onderwerp dat thans aan de orde is. Maar ik wil mij toch aansluiten bij de Blaey, die zegt dat het uit beroepsoverwegingen gewenst is dat tot een dergelijke stap slechts in uiterste omstandigheden wordt overgegaan, als alle mogelijkheden uitgeput zijn.

De prae-adviseur Sanders, die ook in de ambtenaar-accountant allereerst de ambtenaar ziet, komt, anders dan de Blaey, in zijn derde stelling tot de conclusie, dat de publiekrechtelijke plicht van de ambtenaar, volgens art. 162 Strafvordering, in strijd komt met de geheimhoudingsplicht, welke de accountant als N.I.v.A.-lid heeft aanvaard. 7) Ik kan het hier niet mee eens zijn; ik zie die strijd niet. Zoals ik hierboven, bij de bespreking van het prae-advies de Blaey, reeds uiteenzette, brengt de algemene opdracht van de ambtenaar-accountant mee, dat hij aangifte doet van de in de uitoefening zijner bediening ter kennis gekomen strafbare feiten. $\mathrm{H}_{\mathrm{ij}}$ doet dan geen ",andere mededelingen" dan de uitvoering van zijn opdracht van hem, ambtenaar en accountant, eist.

Het prae-advies van collega Lindner beperkt zich tot een bespreking van de zwijgplicht en zegt o.a.: „Het komt hier aan op de vraag, welke mededelingen mogen worden gedaan en of hier een conflict kan ontstaan voor de accountant die tevens ambtenaar is". ${ }^{8}$ )

Even later citeert hij artikel 29b van de Landbouwcrisiswet 1939 en voegt daaraan toe: „Op grond van mijn ervaring aan de Economische „Departementen kan ik zeggen, dat verschillende Ministers, die deze „Departementen hebben geleid, deze bepaling zó hebben geinterpreteerd, "dat het de betrokken ambtenaren verboden is van op grond van door ,hen ingestelde onderzoekingen te hunner kennis gekomen feiten mede",delingen te doen, ook aan andere Overheidsinstanties". 9) Maar weer wat later zegt hij: „De algemene verplichting van art. 162 Wetboek van .,Strafvordering, tot het doen van aangifte van strafbare feiten aan de „Officier van Justitie of Openbaar Ministerie, waarop ook reeds collega ",de Blaey gewezen heeft, acht ik evenmin als collega van Essen in ",strijd te komen met de geheimhoudingsplicht van de accountant. Ieder "dient te weten dat op de accountant-ambtenaar deze verplichting rust ..(cursivering van mij, v. E.). Als ambtenaar heeft hij een algemene "opdracht, waardoor hij, ook indien hij andere feiten rapporteert, dan

7) M.A.B. Juli 1948, blz. 204.

8) M.A.B. Juni 1948, blz. 173

9) M.A.B. Juni 1948, blz. 173.

m a b blz. 269 
,uit zjin speciale opdracht voortvloeien, indien dit althans overtredingen ,zijn, welke hij op grond van zijn algemene opdracht moet rapporteren, ,niet in botsing komt met art. 2 van het Reglement van Arbeid van het "Instituut. Ook indien hij een strafbaar feit rapporteert, tot het opsporen .,waarvan hij geen opdracht verkreeg, doet hij geen andere medede, lingen dan voor de uitvoering van zijn algemene opdracht worden ".vereist". 10)

Dus: de accountants van het Ministerie van Economische Zaken mogen geen mededelingen doen aan andere Overheidsinstanties; hun hoogste chef, de Minister van Economische Zaken, heeft hun dit verboden. Maar: als zij aangifte doen van een door hen geconstateerd strafbaar feit, ook als dit ligt op ander gebied dan dat van hun eigenlijke werk, dan voldoen zij aan de hun in art. 162 Strafvordering opgelegde verplichting. ,Ieder dient te weten dat op de accountant-ambtenaar deze verplichting rust".

Aan het slot van zijn prae-advies spreekt Lindner over het gebruik dat kan worden gemaakt van de rapporten, die de accountants in Overheidsdienst hebben uitgebracht. Hij zegt dat, hoewel deze collega's op dit gebruik geen directe invloed hebben, zij toch zullen gevoelen dat het niet juist is dat deze rapporten in voorkomende gevallen worden gebruikt voor andere doeleinden dan waarvoor ze zijn uitgebracht. De praeadviseur behandelt het geval dat een Overheids-accountant een onderzoek heeft ingesteld naar een kostprijs bij een industriële onderneming. De onderneming heeft stevig verdiend en er rijst twijfel of de hoge winsten wel fiscaal zijn verantwoord. Het zou nu onaangenaam zijn als het rapport van de accountant van Economische Zaken door het Ministerie ter verificatie aan de belastingautoriteiten zou worden toegezonden; onaangenaam niet alleen voor de ondernemer, maar ook voor de betrokken accountant. Immers zou het vertrouwen, dat het publiek in de ambtenaar-accountant stelt, worden geschaad. Maar, vraag ik, als nu eens geen twijfel zou rijzen of de hoge winst wel fiscaal is verantwoord, maar als de accountant van Economische Zaken bij zijn onderzoek de zekerheid zou hebben gekregen dat de winst fiscaal niet is verantwoord, zou dan die accountant niet, ingevolge art. 162 Strafvordering, de plicht hebben dit strafbare feit te rapporteren? M.i. wel! Nog eens: ieder dient te weten dat op de accountant-ambtenaar deze verplichting rust.

Lindner eindigt zijn prae-advies met de opmerking, dat de ambtenaaraccountant het in belangrijke mate zelf in de hand heeft de geheimhouding van zijn rapporten te bevorderen, ook al zou men juridisch kunnen stellen, dat alle organen van de Staat recht hebben op kennisneming van het resultaat van zijn onderzoek. Rekening houdende met de thans geldende wettelijke bepalingen kan ik mij bij dit laatste geheel aansluiten.

De prae-adviseur Toutenhoofd ziet in de accountant in overheidsdienst eerst de accountant, dan de ambtenaar. De ambtenaar is ingevolge art. 59 Rijksambtenarenreglement tot geheimhouding verplicht; de plicht tot geheimhouding van de accountant zou groter zijn. „Als zodanig zijn wij n.l. verplicht ons te onthouden van alle mededelingen die niet nood"zakelijk zijn voor de uitvoering van de opdracht". 11) Zou de ambtenaar dan wel mededelingen mogen doen die niet noodzakelijk zijn voor de uitvoering van zijn opdracht?

10) M.A.B. Juni 1948, blz. 174.

11) M.A.B. Juli 1948, blz. 205. 
Collega Toutenhoofd vraagt zich vervolgens af, of de accountant in overheidsdienst aanspraak zal kunnen maken op een verschoningsrecht. Zich beroepende op de inleiding door mij gehouden op de 31 ste Accountantsdag, waarin ik zou hebben gesteld dat de accountant in het algemeen het verschoningsrecht toekomt, neemt Toutenhoofd aan dat ook de overheidsaccountants zich op deze exceptie zullen kunnen beroepen. Ik mag hier opmerken dat ik in de genoemde inleiding niet heb gesteld dat de accountant in het algemeen het verschoningsrecht dient toe te komen; ik heb integendeel de mening uitgesproken dat dit recht zou moeten worden gereserveerd voor de openbare accountant. De openbare accountant immers is de vertrouwensman tot wie het publiek zich zonder terughouding moet kunnen wenden teneinde hulp en voorlichting te verkrijgen en dit zal te onbeschroomder kunnen geschieden naar mate meer zekerheid bestaat dat hetgeen de openbare accountant wordt toevertrouwd bij hem veilig is, zelfs voor de rechter. Die mogelijkheid tot onbeschroomde raadpleging is een zodanig groot algemeen belang, dat daarvoor dat andere algemene belang, de zo volledig mogelijke voorlichting van de rechter, heeft te wijken.

Bij de accountant in overheidsdienst ligt de zaak anders; het publiek komt niet tot hem om hulp en voorlichting; hij is niet de vertrouwensman van het maatschappelijk verkeer, die onbeschroomd geraadpleegd moet kunnen worden. Ik ben dus van mening dat hij uit dien hoofde zich niet op een verschoningsrecht zal kunnen beroepen. Deze mening is niet in strijd met de overwegingen in de beslissing van Mr. van Lier, die ik hiervoor citeerde. Mr. van Lier kent de betrokken accountant met betrekking tot bepaalde zaken een verschoningsrecht toe, niet omdat hij accountant is maar belasting-ambtenaar, aan wie in de door Mr. van Lier genoemde wetten een geheimhoudingsplicht is opgelegd.

Collega Toutenhoofd brengt de artsen-ambtenaren ter sprake. Ik moet erkennen niet volledig op de hoogte te zijn hoe deze vragen in de artsenwereld liggen; ik ben er evenwel niet zeker van dat het verschoningsrecht van een keurend of controlerend arts zou worden erkend. 12)

De prae-adviseur spreekt ook over de zorgvuldigheid die de overheidsaccountants moeten in acht nemen bij het redigeren van hun rapporten; de redactie daarvan moet zodanig zijn dat niet onnodig geheimen worden bekend gemaakt. Ik kan mij daarbij natuurlijk volkomen aansluiten. Ik kan mij evenwel niet verenigen met hetgeen Toutenhoofd daarop laat volgen: „Indien een ambtenaar - niet accountant - van zijn chef de .,opdracht krijgt, dergelijke niet terzake dienende mededelingen te rap.,porteren, dan is hij verplicht daaraan gevolg te geven. Hij kan zich ,nergens op beroepen, wanneer hij weigert. Wij als accountants kunnen ,,dat wel, wij verwijzen naar ons beroepsgeheim voor de collega's-insti"tuutsleden neergelegd in het Reglement van Arbeid". 13) Ik acht een zodanige opdracht onrechtmatig en de ambtenaar - niet accountant die van zijn chef een dergelijke opdracht krijgt zal zich tot een hogere chef dienen te wenden teneinde die opdracht te doen intrekken. En dit zal ook de ambtenaar-accountant hebben te doen.

12) Zie Mr. Dr. R. Bromberg: Het recht en de geneesheer, Haarlem 1926, blz. 32: Slechts dan mag en moet de arts zijn plicht tot getuigen nakomen, indien er noch sprake is van art. 272 Wetboek van Strafrecht, noch van verschoningsrecht, b.v. indien het feiten geldt die de arts in een andere hoedanigheid dan van behandelend geneesheer zijn bekend geworden, b.v. als controlerend, keurend of gerechtelijk deskundige.

13) M.A.B. Juli 1948, blz. 207. 
Enkele conclusies meen ik ten besluite te mogen trekken:

1. In beginsel is de ambtenaar-accountant verplicht strafbare feiten, ook al liggen deze niet op zijn eigen terrein, te rapporteren.

2. Uit opportuniteits-overwegingen is hem voorgeschreven geen aangifte te doen van strafbare feiten, alvorens met het Departement waaronder hij ressorteert overleg te hebben gepleegd.

3. De ambtenaar-accountant, die gevolg geeft aan het gestelde onder 1 en 2 komt niet in strijd met de geheimhoudingsplicht van art. 2 R.v.A.

\title{
EEN ENGELSE VISIE OP HET VRAAGSTUK VAN DE AFSCHRIJ- VINGEN OP DUURZAME SLIJTENDE PRODUCTIEMIDDELEN
}

\author{
door Drs L. J. M. Roozen
}

Ook in Engeland houdt het vraagstuk van de afschrijvingen op de duurzame, slijtende productiemiddelen bij het huidige prijspeil de gemoederen bezig.

F. R. M. de Paula heeft hierover een lezing gehouden op een verenigde vergadering van de Engelse accountantsverenigingen op $18 \mathrm{Mei}$ j.l., waarvan een verslag verschenen is in .,The accountant van 5 Juni 1948 . I $k$ wil de aandacht vestigen op enige merkwaardige punten in het betoog van de Paula, welke m.i. evenzovele misvastingen inhouden.

De Paula begint met te stellen, dat de prijsstijging van de laatste jaren een verschijnsel is van inflatie.

$\mathrm{H}_{\mathrm{ij}}$ neemt niet aan, dat het prijspeil nog wel weer eens kan dalen: "There seems little indication that this is a temporary phase".

Volgens de Paula moet aan de blijvende grotere vermogensbehoefte van het bedrijf worden voldaan van buitenaf, d.w.z. uit nieuwe besparingen. Daarbij is het niet noodzakelijk dat deze besparingen geschieden uit de, op basis van de uitgaafprijs der productiemiddelen vastgestelde .,winst' 'van hetzelfde bedrijf.

Hieruit volgt zijn conclusie, dat de accountant een afschrijving op basis van de vervangingswaarde, en een ,inhalen" van de te lage af schrijvingen in het verleden uit de "winst", niet behoeft te eisen.

De extra-afschrijving door stijging van de vervangingswaarde is volgens de Paula niet een "charge against earnings" maar een "appropiation" (besteding). Daarom is dit vraagstuk "obviously a matter of financial policy with which the auditor as such is not concerned", want "financial policy is clearly of concern only to the board and members of a company".

Volgens de Paula is de eis van de afschrijving op vervangingswaarde afkomstig van de "economists" (lees: sociaal-economen), die uit de jaarrekeningen gegevens willen putten voor hun berekeningen van het nationale inkomen en de nationale investering.

Behalve zijn axioma, dat de prijsstijging een blijvende is - hij vraagt zich niet af, in hoeverre zijn betoog anders wordt, wanneer zij als een tijdelijk verschijnsel moet worden beschouwd! - voert de Paula de volgende argumenten voor zijn standpunt aan:

1. De vervanging ligt nog in de toekomst en wij kunnen het prijspeil in de toekomst niet schatten. 